\title{
HUBUNGAN PENGGUNAAN TIK DENGAN KINERJA PPL DI BP3K JATI AGUNG KABUPATEN LAMPUNG SELATAN
}

\author{
(The Relation Between Information and Communication Technology Usage and Extension \\ Workers' Performance at BP3K Jati Agung Regency South Lampung District)
}

M Nuzul Mubarokah, Dame Trully Gultom, Suarno Sadar

Jurusan Agribisnis, Fakultas Pertanian, Universitas Lampung, Jl. Prof. Dr. Soemantri Brojonegoro No.1 Bandar Lampung 35141, Telp 082280013001, e-mail: mnuzulmubarokah@gmail.com

\begin{abstract}
The study aims to know the level of Information and Communication Technology (ICT) usage, the level of Extension Workers' performance, the relation between the use of ICT and the performance of Extension Workers, and factors related to the use of ICT in Agricultural Extension Centers, Fisheries and Forestry (BP3K) Jati Agung, South Lampung District. This study was conducted at BP3K Jati Agung Regency, South Lampung District in 2017 with 17 respondents of Extension Workers. The research method used is a survey method. Methods of analysis used were descriptive analysis and Rank Spearman correlation. The results showed that Extension Workers have a high rate of ICT utilization and a high performance level. The use of ICT has a significant relationship with the performance of Extension Workers and factors related to the use of ICT are age, education, income, and cosmopolitan characteristics.
\end{abstract}

Key words: extension workers, ICT, performance

\section{PENDAHULUAN}

Penyuluhan pertanian dalam pembangunan pertanian memiliki peran sentral sebagai fasilitator yakni menyampaikan informasi dari luar yakni sub sistem ilmuwan kepada sistem sosial masyarakat pengguna (petani). Proses penyuluhan pertanian menuntut penyuluh mampu berkomunikasi dan memanfaatkan media penunjang yang ada sehingga penyuluhan dapat berjalan efektif dan efisien.

Salah satu permasalahan penyuluhan pertanian dalam pelaksanaannya adalah sumberdaya manusia yaitu keterbatasan tenaga penyuluh pertanian baik dari segi kuantitas maupun kualitasnya (Kementerian Pertanian, 2014). Berdasarkan penelitian Sari (2015) tentang kinerja penyuluh pertanian menyimpulkan bahwa kinerja penyuluh pertanian masih dalam kategori cukup. Penelitian yang sama oleh Santi, D. Nikmatullah, dan R.T. Prayitno (2016) menyimpulkan bahwa kinerja penyuluh pertanian masih tergolong rendah. Hal ini menunjukkan kinerja penyuluh pertanian masih kurang maksimal dalam melakukan kegiatan penyuluhan. Menurut Peraturan Menteri Pertanian No. 01/Permentan/OT.140/1/2008 tentang Pedoman Pembinaan Tenaga Harian Lepas (THL) Tenaga Bantu Penyuluh Pertanian (TBPP) menerangkan bahwa dalam upaya melakukan percepatan pembangunan pertanian antara lain ditempuh melalui revitalisasi penyuluhan pertanian dengan kebijakan satu desa satu penyuluh guna meningkatkan pendapatan dan kesejahteraan petani dan keluarganya dengan merekrut Tenaga Harian Lepas (THL) Tenaga Bantu Penyuluh Pertanian (TBPP). Penelitian Santi (2016) menerangkan jumlah penyuluh pertanian (11 orang) belum sebanding dengan jumlah desa ( 23 desa) yang ada sehingga menyebabkan masing-masing penyuluh pertanian mendapat dua hingga tiga desa. Hal ini menunjukkan kebijakan satu penyuluh satu desa belum berjalan secara maksimal.

Undang-undang No. 16 tahun 2006 tentang Sistem Penyuluhan Penyuluhan Pertanian, Perikanan, dan Kehutanan pasal 31 ayat 1 mengamanatkan perlunya meningkatkan kapasitas kelembagaan penyuluhan dan kinerja penyuluh melalui sarana dan prasarana memadai agar penyuluhan dapat diselenggarakan secara efektif dan efisien. Penyuluh dituntut tahu dan menguasai meteri penyuluhan dan berbagai informasi pertanian dengan cepat dan tepat sehingga penyuluh harus dapat mengikuti perkembangan akses informasimelalui pemanfaatan TIK.

Teknologi Informasi dan Komunikasi (TIK) merupakan teknologi yang menggabungkan komputasi dengan jalur komunikasi berkecepatan 
tinggi yang membawa data, suara, dan video (informasi) (William dan Sawyer dalam Supriyadi dan Kiswanto, 2010). TIK dalam penyuluhan pertanian memiliki peran sebagai alat bantu menerima dan menyampaikan informasi bidang pertanian yang digunakan oleh PPL untuk melakukan kegiatan penyuluhan pertanian. Berdasarkan kebijakan pemerintah dalam Peraturan Menteri Pertanian No. 16/Permentan/OT.140/2/2013 tentang Pedoman Sistem Manajemen Informasi Penyuluhan Pertanian di Lingkungan Kementerian Pertanian menerangkan bahwa penggunaan teknologi informasi bertujuan dalam rangka percepatan informasi penyuluhan pertanian agar efektif dan efisien. Sistem jaringan yang terkoneksi diharapkan mampu meningkatkan produktivitas kerja penyuluh dan penyuluhan, dalam pelayanan yang efisien, cepat, mudah, akurat, murah, aman, terpadu dan akuntabel. Oleh karena itu pemerintah menerapkan sistem manajemen informasi penyuluh pertanian yang dilakukan melalui pelayanan dengan memanfaatkan teknologi informasi.

Kabupaten Lampung Selatan memiliki total produksi Jagung sebanyak 632.137 ton dan luas panen seluas 121.985 ha. Kabupaten Lampung Selatan memiliki jumlah produksi dan luas panen yang terbesar dibandingkan dengan kabupaten/kota lainnya di Provinsi Lampung, namun tingkat produktivitasnya masih belum optimal dan berada pada urutan ketiga setelah Kabupaten Lampung Timur dan Kabupaten Lampung Tengah. Salah satu kecamatan di Kabupaten Lampung Selatan yang menjadi sentra produksi jagung adalah Kecamatan Jati Agung. Kecamatan Jati Agung merupakan kecamatan yang memiliki jumlah penyuluh kedua terbanyak di Kabupaten Lampung Selatan

Menurut Sumardjo, Baga dan Mulyandari (2010) TIK memiliki peranan yang sangat penting untuk mendukung kegiatan pembangunan pertanian berkelanjutan. Pembangunan pertanian dengan memanfaatkan TIK merupakan hal yang saling berpengaruh satu sama lain (determinisme). Pemanfaatan TIK adalah salah satu faktor yang paling penting dalam peningkatan produksi dengan memaksimalkan informasi pertanian sehingga dapat mendorong ke arah pembangunan yang diharapkan.

Penyuluh pertanian di BP3K Jati Agung Lampung Selatan berjumlah 17 orang. BP3K Jati Agung Lampung Selatan memiliki jumlah PPL THL TBPP terbanyak. Berdasarkan hasil pra turun lapangan, penyuluh pertanian THL TBPP memiliki umur yang lebih muda (rata-rata 34,70 tahun) dibandingkan dengan PPL PNS (rata-rata 47,43 tahun). Menurut Soekartawi (1988), semakin muda umur semakin cepat melakukan adopsi inovasi walaupun sebenarnya masih belum berpengalaman dalam soal adopsi inovasi tersebut. Adopsi inovasi yang dimaksud adalah penggunaan TIK bagi Penyuluh Pertanian Lapangan (PPL). Jumlah penyuluh pertanian di Kecamatan Jati Agung Lampung Selatan belum sebanding dengan 21 desa yang ada di Kecamatan Jati Agung, sehingga menyebabkan masih terdapat penyuluh pertanian yang mendapatkan dua desa untuk cakupan wilayah kerja penyuluh. Hal tersebut merupakan permasalahan yang diduga dapat berkaitan dengan kinerja penyuluh pertanian yang ada di BP3K Jati Agung Lampung Selatan.

Berdasarkan uraian tersebut, maka tujuan dari penelitian ini adalah untuk mengetahui tingkat penggunaan TIK, tingkat kinerja PPL, faktorfaktor yang berhubungan dengan penggunaan TIK, dan hubungan antara penggunaan TIK dengan kinerja PPL.

\section{METODE PENELITIAN}

Metode penelitian yang digunakan adalah metode survei dengan unit sampel sebanyak 17 responden. Penelitian ini dilakukan di BP3K Jati Agung Lampung Selatan. Lokasi penelitian dipilih secara sengaja (purposive) dengan pertimbangan KecamatanJati Agungmerupakan salah satu sentra produksi jagung di Kabupaten Lampung Selatan dandi BP3K Jati Agung memiliki PPL THL TBPP terbanyak di Kabupaten Lampung Selatan. Pengambilan data dilakukan pada bulan Mei 2017. Data yang digunakan dalam penelitian ini adalah data primer dan data sekunder. Data primerdiperoleh secara langsung melalui proses wawancara dan kuesioner. Data sekunder diperoleh dari badan dan instansi terkait di daerah penelitian.

Metode analisis data yang digunakan pada penelitian ini adalahanalisis deskriptif, sedangkan pengujian hipotesis menggunakan analisis inferensial yakni statistik nonparametrik korelasi Rank Spearman (Siegel 1986). Pengujian hipotesis untuk mengetahui apakah terdapat hubungan antara faktor-faktor yang diduga berhubungan dengan penggunaan TIK dengan penggunaan TIK, dan hubungan antara penggunaan TIK oleh PPL dengan kinerja PPL. Data primer yang diperoleh pada penelitian ini merupakan data oridnal 
sehingga perlu dikonversi menggunakan metode MSI (Method Successive Interval) untuk mengubah data ordinal menjadi interval.

Kriteria pengambilan keputusan:

1. Jika rs hitung $<$ rs tabel pada $\alpha=0,05$, maka terima Ho. Berarti tidak terdapat hubungan yang nyata antara variabel dependen dan variabel independen.

2. Jika rs hitung $\geq$ rs tabel pada $\alpha=0,05$ maka tolak Ho. Berarti terdapat hubungan yang nyata antara variabel dependen dan variabel independen.

\section{HASIL PENELITIAN}

\section{Gambaran Umum Daerah Penelitian}

BP3K Kecamatan Jati Agung sudah ada sejak tahun 1976 dengan nama BPP. Semula BPP Kecamatan Jati Agung masih dalam wilayah Kecamatan Kedaton (Kedaton dan Tanjung Bintang). Pada tahun 1983 menjadi BPP Tanjung Bintang, dengan wilayah Natar dan Tanjung Bintang. Tahun 1995 menjadi BPP Tanjung Bintang dengan wilayah Tanjung Bintang dan Jati Agung. Tahun 2002 menjadi BPP Jati Agung yang memiliki 21 desa binaan. Mulai tahun 2012 nama BPP berubah nama menjadi BP3K sampai saat ini.

BP3K Kecamatan Jati Agung berlokasi di Desa Fajar Baru Jalan RA. Basyid Kecamatan Jati Agung Kabupaten Lampung Selatan. Kecamatan Jati Agung terletak paling Utara Kabupaten Lampung Selatan dan terbentuk berdasarkan Undang- Undang No. 22 Tahun 1999, Surat Menteri Dalam Negeri Nomor: 188.138/173/POUD tanggal 17 Juni 1999 perihal petunjuk pelaksanaan Peraturan Pemerintah No. 46 Tahun 1999 dan Surat Keputusan Gubernur/KDH TK.I Lampung tanggal 13 Agustus 1999 No. 81 Tahun 1999. Meresmikan Kecamatan Jati Agung dengan Ibu Kota Marga Agung. Kecamatan Jati Agung terdiri dari 21 desa, 516 RT (Rukun Tetangga), 122 RW (Rukun Warga), dan 126 dusun.

BP3K Jati Agung Lampung Selatan memiliki jumlah PPL sebanyak 17 PPL (7 PPL PNS dan 10 PPL THL TBPP). Kelembagaan yang terbentuk dalam upaya pengembangan bidang pertanian yakni 264 kelompok tani pangan dan hortikultura, 14 gapoktan dan 18 kelompok wanita tani. Adapun beberapa kegiatan yang pernah dilakukan adalah pelaksanaan PRA, penyusunan RKPP dan
Programa, penyusunan media informasi, pertamuan dan pelatihan PPL.

\section{Tingkat Umur Responden}

Umur $\left(\mathrm{X}_{1}\right)$ merupakan lamanya waktu hidup PPL pada saat penelitian dilaksanakan. Pengelompokkan umur pada penelitian ini dibagi dalam tiga kategori berdasarkan teori Setyonegoro (1974) yakni usia dewasa muda (18-25 tahun), usia dewasa penuh (25-60 tahun) dan usia lanjut (>60 tahun). Sebaran umur PPL dapat dilihat pada Tabel 1.

Berdasarkan Tabel 1 menunjukkan 16 PPL yang termasuk dalam kategori dewasa penuh. Rata-rata umur PPL adalah 39,94 yang termasuk dalam kategori dewasa penuh.Usia dewasa penuh merupakan usia yang matang secara fisik dan psikis serta kaya pengalaman sehingga dianggap mampu melaksanakan tugas lebih baik.

\section{Tingkat Pendidikan Formal}

Tingkat pendidikan formal $\left(\mathrm{X}_{2}\right)$ merupakan tingkat pembelajaran tertinggi yang diikuti PPL di bangku sekolah formal pada saat penelitian dilaksanakan. Tingkat pendidikan formal PPL di BP3K Jati Agung Lampung Selatan terbagi menjadi tiga kategori yakni tingkat pendidikan SMA/sederajat, Diploma dan Sarjana. Berdasarkan Tabel 2 menunjukkan 11 PPL $(64,71)$ merupakan lulusan Sarjana. Banyaknya PPL yang merupakan lulusan pendidikan tinggi dirasa menjadi penunjang bagi PPL dalam melaksanakan tugasnya dengan lebih baik.

Tabel 1. Sebaran umur PPL di BP3K Jati Agung Lampung Selatan

\begin{tabular}{llcr}
\hline Umur (tahun) & Kategori & $\begin{array}{c}\text { Responden } \\
\text { (orang) }\end{array}$ & $\begin{array}{r}\text { Persentase } \\
(\%)\end{array}$ \\
\hline $18-25$ & Dewasa muda & 1 & 5,88 \\
$26-60$ & Dewasa penuh & 16 & 94,12 \\
$>60$ & Lanjut usia & 0 & 0,00 \\
\hline Jumlah & & 17 & 100,00 \\
\hline Rata-rata & 39,94 (Dewasa penuh) & \\
\hline
\end{tabular}

Tabel 2. Sebaran pendidikan formal PPL BP3K di Jati Agung Lampung Selatan

\begin{tabular}{lcc}
\hline Kategori & $\begin{array}{c}\text { Responden } \\
\text { (orang) }\end{array}$ & $\begin{array}{c}\text { Persentase } \\
(\%)\end{array}$ \\
\hline SLTA/Sederajat & 2 & 11,76 \\
Diploma & 4 & 23,53 \\
Sarjana & 11 & 64,71 \\
\hline Jumlah & 17 & 100,00 \\
\hline
\end{tabular}


Tabel 3. Tingkat penghasilan PPL di BP3K Jati Agung Lampung Selatan

\begin{tabular}{llrr}
\hline $\begin{array}{c}\text { Interval tingkat } \\
\text { penghasilan } \\
(\text { Rp000/bulan) }\end{array}$ & Kategori & $\begin{array}{c}\text { Responden } \\
\text { (orang) }\end{array}$ & $\begin{array}{c}\text { Persentase } \\
(\%)\end{array}$ \\
\hline $1.200-2.733$ & Rendah & 10 & 58,82 \\
$2.733-4.266$ & Sedang & 3 & 17,65 \\
$4.266-5.800$ & Tinggi & 4 & 23,53 \\
\hline Jumlah & & 17 & 100,00 \\
\hline Rata-rata & 3.050 (Sedang) & & \\
\hline
\end{tabular}

\section{Tingkat Penghasilan}

Tingkat penghasilan adalah pendapatan perbulan yang diperoleh PPL dari pekerjaannya sebagai Penyuluh dan pekerjaan sampingan. Tingkat penghasilan PPL pada penelitian ini dibagi menjadi tiga kategori rendah, sedang dan tinggi (Tabel 3). Berdasarkan Tabel 3 menunjukkan 10 PPL $(58,82 \%)$ berada dalam kategori rendah. Rata-rata penghsasilan PPL sebesar Rp3.050.000,00 yang berada dalam kategori sedang.

\section{Tingkat Motivasi}

Motivasi merupakan sesuatu yang mendorong PPL untuk melakukan tindakan. Pengukuran tingkat motivasi pada penelitian ini dilakukan dengan menggunakan skor (skala ordinal) kemudian dinaikkan ke skala interval dengan bantuan MSI. Kategori dibagi menjadi rendah, sedang, dan tinggi (Tabel 4).

Berdasarkan Tabel 4 menunjukkan 5 PPL $(29,42 \%)$ berada dalam kategori rendah. Rata-rata skor tingkat motivasi sebesar 36,03 yang berada dalam kategori sedang.

\section{Tingkat Kekosmopolitan}

Kekosmopolitan merupakan keluasan wawasan dan keterbukaan penyuluh terhadap berbagai informasi dari luar dirinya. Menurut Soekartawi (1988), pola hubungan/kekosmopolitan adalah apakah seseorang berada dalam lingkup pola hubungan kosmopolitas atau lokalitas. Biasanya orang yang berada dalam pola hubungan yang kosmopolitas akan lebih cepat melakukan adopsi inovasi. Pengukuran variabel tingkat kekosmopolitan dilakukan dengan menggunakan skor (skala ordinal) kemudian dinaikkan ke skala interval dengan bantuan MSI dan dikategorikan menjadi rendah, sedang, dan tinggi (Tabel5).

Tabel 5 menunjukkan sebanyak 9 PPL (52,94\%) berada dalam kategori tinggi. Rata-rata skor kekosmopolitan sebesar 10,64 yang berada dalam kategori tinggi. Tingginya kekosmopolitan PPL ini salah satunya disebabkan oleh semua PPL pernah melakukan kegiatan ke luar lingkungan kerja dalam rangka menambah wawasan atau informasi pertanian untuk dirinya sendiri. Tempat yang mereka kunjungi adalah BPTP Lampung, Dinas Pertanian, BPP Lampung, Perpustakaan Umum, dan Hortipark.

\section{Tingkat Persepsi}

Persepsi merupakan penilaian PPL terhadap TIK dalam bidang pertanian. Persepsi penyuluh dalam hal ini berdasarkan teori sifat adopsi inovasi (Soekartawi, 1988) yaitu yakni kompatibilitas (kesesuaian), kompleksitas (kerumitan), triabilitas (kemudahan dicoba) dan observabilitas. Pengukuran variabel tingkat persepsi dilakukan dengan menggunakan skor (skala ordinal) kemudian dinaikkan ke skala interval dengan bantuan MSI dan dikategorikan berdasarkan rendah, sedang dan tinggi (Tabel 6).

Tabel 4. Tingkat motivasi PPL di BP3K Jati Agung Lampung Selatan

\begin{tabular}{llcc}
\hline $\begin{array}{c}\text { Interval tingkat } \\
\text { motivasi }\end{array}$ & Kategori & $\begin{array}{c}\text { Responden } \\
\text { (orang) }\end{array}$ & $\begin{array}{c}\text { Persentase } \\
(\%)\end{array}$ \\
\hline $28,00-33,18$ & Rendah & 5 & 29,42 \\
$33,19-38,37$ & Sedang & 6 & 35,29 \\
$38,37-43,56$ & Tinggi & 6 & 35,29 \\
\hline Jumlah & \multicolumn{3}{c}{17} \\
\hline Rata-rata & 36,03 (Sedang) \\
\hline
\end{tabular}

Tabel 5. Tingkat kekosmopolitan PPL di BP3K Jati Agung Lampung Selatan

\begin{tabular}{lllc}
\hline $\begin{array}{l}\text { Interval tingkat } \\
\text { kekosmopolitan }\end{array}$ & Kategori & $\begin{array}{c}\text { Responden } \\
\text { (orang) }\end{array}$ & $\begin{array}{c}\text { Persentase } \\
(\%)\end{array}$ \\
\hline $7,01-8,78$ & Rendah & 3 & 17,65 \\
$8,78-10.54$ & Sedang & 5 & 29,41 \\
$10,54-12,31$ & Tinggi & 9 & 52,94 \\
\hline Jumlah & \multicolumn{3}{c}{17} \\
\hline Rata-rata & 10,64 (Tinggi) \\
\hline
\end{tabular}

Tabel 6. Tingkat persepsi PPL di BP3K Jati Agung Lampung Selatan

\begin{tabular}{llll}
\hline $\begin{array}{c}\text { Interval tingkat } \\
\text { persepsi }\end{array}$ & Kategori & $\begin{array}{c}\text { Responden } \\
\text { (orang) }\end{array}$ & $\begin{array}{c}\text { Persentase } \\
(\%)\end{array}$ \\
\hline $57,26-69,49$ & Rendah & 6 & 35,29 \\
$69,49-81,72$ & Sedang & 10 & 58.82 \\
$81,72-93,94$ & Tinggi & 1 & 5,88 \\
\hline Jumlah & \multicolumn{3}{c}{17} \\
\hline Rata-rata & 72,27 (Sedang) & 100,00 \\
\hline
\end{tabular}


Tabel 7. Tingkat penggunaan TIK oleh PPL di BP3K Jati Agung Lampung Selatan menurut indikator penggunaan TIK

\begin{tabular}{lcr}
\hline Indikator & Rata-rata skor & Kategori \\
\hline $\begin{array}{l}\text { Tingkat durasi penggunaan } \\
\text { TIK (Jam/hari) }\end{array}$ & 5,60 & Sedang \\
$\begin{array}{l}\text { Tingkat frekuensi } \\
\text { penggunaan TIK } \\
\text { (Hari/minggu) }\end{array}$ & 5,53 & Tinggi \\
\hline
\end{tabular}

Berdasarkan Tabel 6 dapat diketahui sebanyak 10 PPL $(58,82 \%)$ memiliki tingkat persepsi sedang, sedangkan 6 PPL $(35,29 \%)$ memiliki tingkat persepsi yang rendahdan seorang PPL yang memiliki tingkat persepsi tinggi $(5,88 \%)$. Ratarata skor persepsi sebesar 72,27 yang berada dalam kategori sedang.

\section{Tingkat Penggunaan TIK}

Penggunaan TIK adalah intensitas akses atau gambaran berapa lama dan sering PPL menggunakan TIK dengan tujuan untuk memenuhi kebutuhan informasi tentang pertanian. Pengukuran tingkat penggunaan TIK oleh PPL dilakukan melalui tiga indikator yaitu durasi, frekuensi dan ragam (De Fleur dalam Elian dkk., 2014). Tingkat penggunaan TIK oleh PPL yang diukur berdasarkan indikator-indikator tersebut dapat dilihat pada Tabel 7.

\section{Ragam Penggunaan TIK}

Ragam penggunaan jenis TIK adalah banyaknya jenis teknologi komunikasi yang digunakan PPL untuk berkomunikasi dalam menyampaikan dan memperoleh informasi seperti laptop, komputer, telepon, handphone, smartphone, radio, dan televisi. Ragam penggunaan TIK oleh PPL dapat dilihat pada Diagram 1.

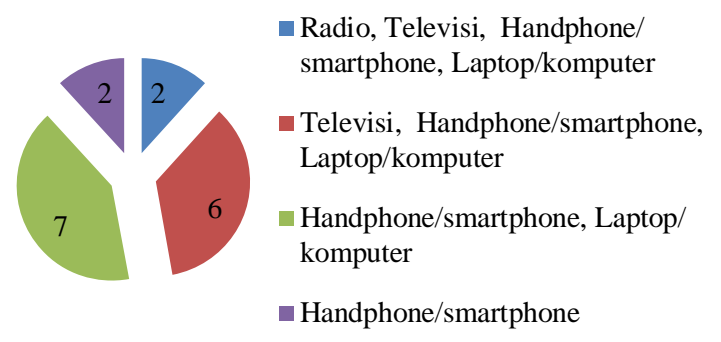

Gambar1. Ragam penggunaan TIK oleh PPL di BP3K Jati Agung Lampung Selatan
Tabel 8. Tingkat penggunaan TIK oleh PPL di BP3K Jati Agung Lampung Selatan

\begin{tabular}{cccc}
\hline $\begin{array}{c}\text { Interval tingkat } \\
\text { penggunaan TIK }\end{array}$ & Kategori & $\begin{array}{c}\text { Responden } \\
\text { (orang) }\end{array}$ & $\begin{array}{c}\text { Persentase } \\
(\%)\end{array}$ \\
\hline $2,00-3,28$ & Rendah & 3 & 17,65 \\
$3,28-4,56$ & Sedang & 3 & 17,65 \\
$4,56-5,84$ & Tinggi & 11 & 64,71 \\
\hline Jumlah & \multicolumn{3}{c}{17} \\
\hline Rata-rata & 4,78 (Tinggi) \\
\hline
\end{tabular}

Berdasarkan indikator-indikator penggunaan TIK oleh PPL, diperoleh hasil pengukuran penggunaan TIK oleh PPL. Pengukuran dilakukan dengan skor kemudian dikonversikan menjadi data interval menggunakan program MSI agar masing-masing indikator dapat dijumlahkan, sehingga diperoleh interval dengan tiga kategori yakni rendah, sedang dan tinggi (Tabel 8).

Berdasarkan Tabel 8 menunjukkan 11 PPL $(64,71 \%)$ memiliki tingkat penggunaan TIK tinggi. Rata-rata skor sebesar 4,78 yang berada dalam kategori tinggi. Tingginya penggunaan TIK oleh PPL disebabkan semua PPL sudah menggunakan alat TIK khususnya Handphone (HP)atau Smartphone. Penggunaan alat TIK ini sudah menjadi kebutuhan dasar PPL dalam melakukan komunikasi jarak jauh kepada sesama PPL dan petani. Selain itu juga menjadi media informasi pertanian dalam rangka menambah pengetahuan PPL untuk melaksanakan tugas. Rata-rata penggunaan TIK oleh PPL dalam sehari selama 5,60 jam, sedangkan rata-rata penggunaan TIK oleh PPL dalam seminggu selama 5,53 hari.

\section{Tingkat Kinerja PPL}

Tingkat kinerja PPL adalah gambaran prestasi atau hasil kerja baik secara kualitas maupun kuantitas yang dicapai penyuluh dalam melaksanakan tugasnya sesuai dengan tanggungjawab yang diberikan kepadanya. Pengukuran tingkat kinerja PPL berdasarkan Peraturan Menteri Pertanian No. 91/Permentan/OT.140/9/2013 tentang Pedoman Evaluasi Kinerja Penyuluh Pertanianmelalui tiga indikator yaitu persiapan penyuluhan pertanian, pelaksanaan penyuluhan pertanian dan evaluasi serta pelaporan penyuluhan pertanian (Tabel 9).

Berdasarkan indikator-indikator pengukuran kinerja PPL, maka dapat diperoleh tingkat kinerja PPL. Sebaran PPL berdasarkan tingkat kinerja dapat dilihat pada Tabel 10. 
Tabel 9. Tingkat kinerja PPL di BP3K Jati Agung Lampung Selatan menurut indikator kinerja PPL

\begin{tabular}{lcc}
\hline \multicolumn{1}{c}{ Indikator } & Rata-rata skor & Kategori \\
\hline Persiapan Penyuluhan & 9,16 & Sedang \\
$\begin{array}{l}\text { Pelaksanaan } \\
\text { Penyuluhan }\end{array}$ & 20,31 & Sedang \\
$\begin{array}{l}\text { Evaluasi dan } \\
\text { Pelaporan Penyuluhan }\end{array}$ & 4,64 & Sedang \\
Pertanian & & \\
\hline
\end{tabular}

Tabel 10. Tingkat kinerja PPL di BP3K Jati Agung Lampung Selatan

\begin{tabular}{clcc}
\hline $\begin{array}{c}\text { Interval tingkat } \\
\text { kinerja PPL }\end{array}$ & Kategori & $\begin{array}{c}\text { Responden } \\
\text { (orang) }\end{array}$ & $\begin{array}{c}\text { Persentase } \\
(\%)\end{array}$ \\
\hline $25,70-29,88$ & Rendah & 3 & 17,65 \\
$29,88-34,06$ & Sedang & 4 & 23,53 \\
$34,06-38,25$ & Tinggi & 10 & 58,82 \\
\hline Jumlah & 17 & 100,00 \\
\hline Rata-rata & 34,11 (Tinggi) & \\
\hline
\end{tabular}

Tabel 10 menunjukkan 10 PPL $(58,82 \%)$ berada dalam kategori tinggi. Rata-rata skor kinerja PPL sebesar 34, 11 yang termasuk dalam kategori tinggi. Hasil ini sama seperti hasil penelitian Janis (2014) yang menerangkan bahwa tingkat kinerja PPL di Kabupaten Kepulauan Sangihe tergolong tinggi namun hasil ini berbeda dangan penelitian Juwita Sari (2015) yang menerangkan tingkat kinerja PPL Kecamatan Pagelaran, Kabupaten Pringsewu berada pada klasifikasi sedang dan penelitian Santi (2016) yang menerangkan PPL di Kecamatan Gadingrejo Kabupaten Pringsewu dalam klasifikasi rendah. Tingginya kinerja PPL di BP3K Jati Agung disebabkan oleh usaha yang dilakukan PPL dalam melaksanakan tugas berdasarkan pedoman evaluasi kinerja penyuluhan pertanian. Berdasarkan pedoman tersebut PPL menjadikan pedoman atau tolak ukur dalam melakukan kegiatan penyuluhan pertanian di wilayah binaan PPL masing-masing.

\section{Pengujian Hipotesis}

\section{Faktor-faktor yang diduga Berhubungan dengan Penggunaan TIK}

Hubungan antara faktor-faktor penggunaan TIK (variabel X) dengan penggunaan TIK (variabel Y1) dan hubungan antara penggunaan TIK (variabel Y1) dengan kinerja PPL (variabel Y2) dianalisis dengan analisis inferensial yakni statistika non parametrik uji korelasi Rank Spearman menggunakan aplikasi SPSS 16.00. Hasil pengujian faktor-faktor yang berhubungan dengan penggunaan TIK oleh PPL dapat dilihat pada Tabel 11.

Tabel 11 menunjukkan variabel yang memiliki hubungan nyata pada taraf kepercayaan 99 persen (**) adalah umur, dan kekosmopolitan sedangkan yang memiliki hubungan nyata pada taraf 95 persen (*) adalah pendidikan dan penghasilan. Variabel motivasi dan persepsi tidak memiliki hubungan dengan penggunaan TIK.

Hubungan antara umur dengan penggunaan TIK memiliki hubungan yang nyata pada taraf kepercayaan 99 persen (**). Hal tersebut didasarkan nilai koefisian korelasi atau rssebesar 0,671 lebih besar daripada nilai tabel harga kritis $r s$ yaitu 0,485 . Nilai koefisien kolerasi sebesar $-0,671$ memiliki hubungan negatifyang dapat diartikan semakin tinggi umur PPLmaka semakin rendah penggunaan TIK. Penelitian ini sejalan dengan teori Slamet (1978)yang menerangkan semakin tua umur seseorang akan semakin lambat dalam menerima suatu pembaharuan atau menerapkan suatu inovasi yang dalam hal ini adalah penggunaan TIK.

Hubungan antara pendidikan dengan penggunaan TIK memiliki hubungan yang nyata pada taraf kepercayaan 95 persen. Hal tersebut didasarkan Nilai koefisian korelasi $(r s)$ sebesar -0,523 lebih besar dibandingkan nilai tabel harga kritis $r s$ yaitu 0,485 . Nilai koefisien kolerasi sebesar $-0,523$ memiliki hubungan negatif yang dapat diartikan semakin tinggi pendidikan PPL maka semakin rendah penggunaan TIK. Hasil penelitian ini berlawanan dengan teori Soekartawi (1988) yang menerangkan bahwa semakin tinggi pendidikan maka semakin cepat melaksanakan adopsi inovasi. Hal ini disebabkan PPL yang memiliki pendidikan yang tinggi merupakan PPL yang usianya tergolong lebih tua. PPL yang usianya lebih tua cenderung rendah menggunakan TIK.

Tabel 11. Hasil analisis faktor-faktor yang diduga berhubungan dangan penggunaan TIK

\begin{tabular}{|c|c|c|c|c|}
\hline No & Variabel X & Variabel Y & Rs & $\begin{array}{l}\text { Sig. (2- } \\
\text { tailed) }\end{array}$ \\
\hline 1. & Umur & & $-0,671 * *$ & 0,003 \\
\hline 2. & Pendidikan & & $-0,523 *$ & 0,031 \\
\hline 3. & Penghasilan & Penggunaan & $-0,494 *$ & 0,044 \\
\hline 4. & Motivasi & TIK & 0,127 & 0,626 \\
\hline 6. & Kekosmopolitan & & $0,872 * *$ & 0,000 \\
\hline 7. & Persepsi & & 0,133 & 0,611 \\
\hline \multicolumn{5}{|c|}{ Keterangan: } \\
\hline$R s$ & \multirow{2}{*}{\multicolumn{4}{|c|}{$\begin{array}{l}\text { : Rank Spearman } \\
\text { : Berhubungan nyata pada taraf kepercayaan } 99 \%\end{array}$}} \\
\hline$* *$ & & & & \\
\hline$*$ & \multicolumn{4}{|c|}{ B Berhubungan nyata pada taraf kepercayaan $95 \%$} \\
\hline
\end{tabular}


Hubungan antara penghasilan dengan penggunaan TIK memiliki hubungan yang nyata pada taraf kepercayaan 95 persen. Hal tersebut didasarkan Nilai koefisian korelasi $(r s)$ sebesar -0,494 lebih besar dibandingkan nilai tabel harga kritis $r s$ yaitu 0,485 . Nilai koefisien kolerasi sebesar $-0,494$ memiliki hubungan negatif yang dapat diartikan semakin tinggi penghasilan PPL maka semakin rendah penggunaan TIK. Hasil penelitian ini berlawanan dengan teori Soekartawi (1988) yang menerangkan bahwa pendapatan yang tinggi seringkali ada hubungannya dengan adopsi inovasi. Hal ini disebabkan PPL yang memiliki penghasilan yang tinggi merupakan PPL yang usianya tergolong lebih tua. PPL yang usianya lebih tua cenderung rendah menggunakan TIK.

Hubungan antara motivasi dengan penggunaan TIK tidak memiliki hubungan yang nyata. Hal tersebut didasarkan Nilai koefisian korelasi $(r s)$ sebesar 0,127 lebih kecil dibandingkan nilai tabel harga kritis $r$ s yaitu 0,485 . Maka diketahui bahwa tidak terdapat hubungan antara motivasi dengan penggunaan TIK. Hal tersebut berarti semakin tinggi atau semakin rendah tingkat motivasi PPL tidak ada hubungannya dengan penggunaan TIK.

Hubungan antara kekosmopolitan dengan penggunaan TIK memiliki hubungan yang nyata pada taraf kepercayaan 99 persen. Hal tersebut didasarkan Nilai koefisian korelasi ( $r s$ ) sebesar 0,872 lebih besar dibandingkan nilai tabel harga kritis $r s$ yaitu 0,485 . Nilai koefisien kolerasi sebesar 0,872 memiliki hubungan positif yang dapat diartikan semakin tinggi kekosmopolitan PPL maka semakin tinggi penggunaan TIK. Hasil penelitian ini sejalan dengan penelitian Mulyandari (2011) yang menerangkan bahwa kekosmopolitan memberikan pengaruh nyata terhadap pemanfaatan teknologi infromasi. Hal ini disebabkan PPL yang memiliki ketertarikan yang tinggi terhadap informasi dari luar dirinya dilihat dari semua PPLpernah keluar lingkungan kerja untuk menambah wawasan dan iinformasi serta menggunakan alat TIK sebagai media informasi dan komunikasi kegiatan penyuluhan.

Hubungan antara persepsi dengan penggunaan TIK tidak memiliki hubungan yang nyata. Hal tersebut didasarkan Nilai koefisian korelasi ( $r s$ ) sebesar 0,133 lebih kecil dibandingkan nilai tabel harga kritis $r s$ yaitu 0,485. Maka diketahui bahwa tidak terdapat hubungan antara persepsi dengan penggunaan TIK. Hal tersebut berarti semakin tinggi atau semakin rendah tingkat persepsi PPL tidak ada hubungannya dengan penggunaan TIK.

\section{Hubungan antara Penggunaan TIK dengan Kinerja PPL}

Hubungan antara penggunaan TIK (Y1) dengan kinerja PPL (Y2) dianalisis menggunakan statistika non parametrik uji korelasi Rank Spearman dengan bantuan SPSS16.00. Hasil pengujian statistik dapat diketahui bahwa terdapat hubungan yang nata antara kinerja PPL dengan penggunaan TIK pada taraf kepercayaan 99 persen. Hal tersebut didasarkan Nilai koefisian korelasi $(r s)$ sebesar 0,881 lebih besar dibandingkan nilai tabel harga kritis $r s$ yaitu 0,485 . Nilai koefisien kolerasi sebesar 0,881 memiliki hubungan positif yang dapat diartikan semakin tinggi kinerja PPLs maka semakin tinggi penggunaan TIK. Hal tersebut disebabkan penyuluh pertanian merasa membutuhkan alat untuk menghubungkan antara penyuluh dengan penyuluh dan penyuluh dengan petani binaannya serta penyuluh dengan pihakpihak yang terkait dalam kegiatan penyuluhan.

Hubungan yang terjalin melalui TIK akan lebih cepat dan efektif sehingga mampu meningkatkan kinerja PPL. Penggunaan TIK juga dapat menunjang PPL dalam mengolah data menjadi sebuah informasi yang bermanfaat untuk kegiatan penyuluhan serta laporan dan evaluasi kegiatan penyuluhan pertanian.

\section{KESIMPULAN}

Tingkat penggunaan TIK oleh PPL di BP3K Jati Agung Lampung Selatan termasuk dalam kategori tinggi dengan nilai skor sebesar 4,78. Faktorfaktor yang berhubung dengan penggunaan TIK adalah umur, pendidikan, penghasilan dan kekosmopolitan sedangkan motivasi dan persepsi tidak berhubungan dengan penggunaan TIK. Tingkat kinerja PPL termasuk dalam kategori tinggi dengan nilai skor sebesar 34,11. Hasil penelitian ditemukan bahwa terdapat hubungan antara penggunaan TIK dengan kinerja PPL. Semakin tinggi penggunaan TIK maka semakin tinggi kinerja PPL.

\section{DAFTAR PUSTAKA}

Departemen Pertanian. 2006. Undang-undang Republik Indonesia No. 16 Tahun 2006 tentang Sistem Penyuluhan Pertanian, Perikanan dan Kehutanan. Deptan. Jakarta.

Elian N, Lubis DP, dan Rangkuti PA. 2014. Penggunaan internet dan pemanfaatan informasi pertanian oleh penyuluh pertanian di Kabupaten Bogor Wilayah Barat. Jurnal 
Komunikasi Pembangunan, 12 (2): 104-109. http://journal.ipb.ac.id/index.php/jurnalkmp /article/view/8666. [18 Januari 2017].

Janis RL. 2014. Kinerja penyuluhan pertanian di wilayah kerja Badan Pelaksana Penyuluhan Pertanian Perikanan dan Kehutanan (BP4K) Kabupaten Kepulauan Sangahie. Jurnal Cocos, 4 (4): 20-41. https://ejournal.unsrat. ac.id / index.php /cocos/article/view/4027. [18 Januari 2017].

Kementerian Pertanian. 2008. Peraturan Menteri Pertanian Nomor 01/Permentan/OT. 140/1/2008 Tentang Pedoman Tenaga Harian Lepas (THL) Tenaga Bantu Penyuluh Pertanian. Kementan. Jakarta. . 2013 . Peraturan Menteri Pertanian Nomor 91/Permentan/OT. 140/9/2013 Tentang Pedoman Evaluasi Peranan Penyuluh Pertanian. Kementan. Jakarta.

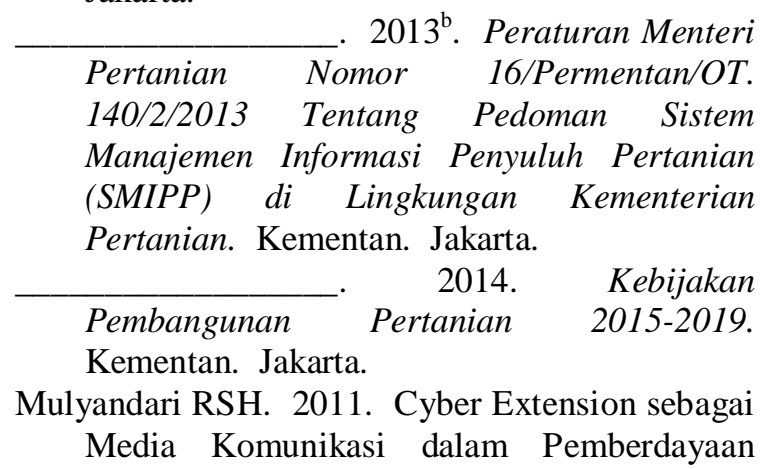

Petani Sayuran. Skripsi. IPB. Bogor. http://repository.ipb.ac.id/handle/123456789/5 1657. [10 Januari 2017].

Santi, Nikmatullah D, dan Prayitno RT. 2016. Tingkat peranan penyuluh tanaman pangan di BP3K Kecamatan Gadingrejo Kabupaten Pringsewu. JIIA, 4 (3): 309-316. http:// jurnal.fp.unila.ac.id/index.php/JIA/ article/ view / 1506. [10 Januari 2017].

Sari J, Nurmayasari I, dan Yanfika H. 2015. Persepsi petani terhadap kinerja penyuluh dalam pengembangan padi organik di Kecamatan Pagelaran Kabupaten Pringsewu. JIIA, 3 (4): 432-439. http://jurnal.fp.unila. ac.id/index.php/JIA/issue/view/105. [18 Januari 2017].

Siegel S. 1986. Statistik Non-Parametrik. PT Gramedia. Jakarta.

Slamet M. 1978. Kumpulan Bacaan Penyuluhan Pertanian Bogor. IPB Press. Bogor.

Soekartawi. 1988. Prinsip Dasar Komunikasi Pertanian. UI Press. Jakarta.

Sumardjo, Baga LM, dan Mulyandari RSH. 2010. Cyber Extension Peluang dan Tantangannya dalam Revitalisasi Penyuluhan Pertanian. IPB Press. Bogor.

Supriyadi E dan Kiswanto MH. 2010. Teknologi Informasi dan Komunikasi. CV Sinar Mandiri. Jakarta. 